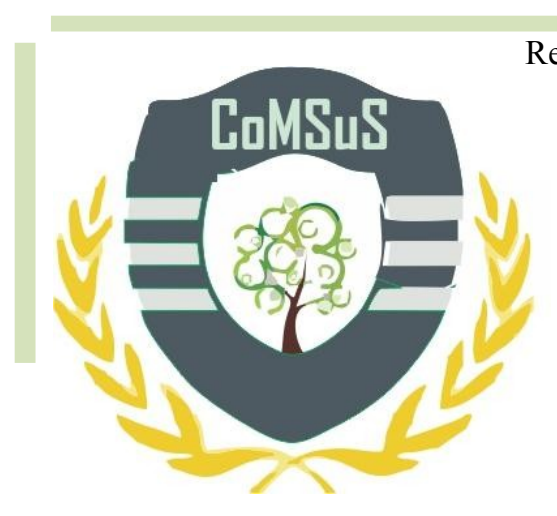

Recebido em 28/03/2017. Revisado em 02/06/2017. Aprovado em 02/06/2017. Editor: Dr. Ivano Ribeiro

Processo de Avaliação: Double Blind Review e-ISSN: $2359-5876$

https://doi.org/10.5935/2359-5876.20170006

\title{
ECO-INOVAÇÃO: UM RELATO DA REPLASTIK RECICLAGEM DE PLÁSTICOS COM MATERIAIS E SUBSTRATOS RECICLADOS E RECICLÁVEIS
}

\section{RESUMO}

Este relatório técnico científico versará sobre as práticas de Gestão Ambiental, Logística Reversa e Ecoinovação à luz do embasamento teórico específico e pelo amparo pragmático mediante descrição da Empresa Replastik Reciclagem de Plásticos, localizada na Cidade de Guarapuava/Paraná. Trata-se de uma pesquisa qualitativa, do tipo descritiva, com objetivos de transcrição do aporte teórico e da articulação com a prática da empresa. Como procedimento de coleta de dados optou-se pelo roteiro de entrevista semiestruturado com o proprietário da empresa e pesquisa documental. Constatou-se um empreendimento consolidado enquanto ideologia de ação e de extrema relevância para toda uma sociedade pelos fins que oportunizam a muitos produtos sem a possibilidade de reinserção no fluxo direto; a empresa se apresenta como uma incubadora pelas práticas vigentes como a busca por produtos novos mediante as prototipagens (próprias) e também econômica (fins lucrativos), bem como, um exemplo de conscientização e adoção de ações ou medidas para a minimização dos impactos ambientais.

Palavras-chave: Gestão Ambiental. Logística Reversa. Eco-inovação.

\section{ECO-INNOVATION: AN ACCOUNT OF REPLASTIK PLASTICS WITH RECYCLED AND RECYCLABLE MATERIALS AND SUBSTRATES}

\begin{abstract}
This scientific technical report refers to the practices of environmental management, logistics and ecoinnovation in the light of the embalming of the specific theorist and the pragmatic protection in the description of the Crosslinking Recycling of Plastics Company, located in the city of Guarapuava / Paraná. It deals with a qualitative research, of descriptive type, with objectives of transcription of the theoretical contribution and of articulation with a practice of the company. As a procedure of data collection for the work of interview with the owner of the company and the documentary search. A project was consolidated in the ideology of action and of extreme relevance for the whole society by the objectives that are presented to many products without possibility of reinsertion not direct flow; The company is presented as an incubator of surveillance practices such as a search for new products such as prototypes (lucrative fines), as well as an example of awareness and adoption of actions or measures to minimize environmental impacts.
\end{abstract}

Keywords: Environmental management. Reverse logistic. Eco-innovation.

\footnotetext{
${ }^{1}$ Mestrando em Administração pela UNICENTRO. E-mail: sandro.rolak2090@gmail.com

2 Doutorado em Energia na Agricultura pela UNESP. Professora do programa de pós-graduação de ADM da Universidade Estadual do Centro Oeste do Paraná - UNICENTRO. E-mail: costa.zo701@gmail.com

${ }^{3}$ Especialista em Engenharia Logística e de Operações Lean pela PUC-PR. Professora da Universidade Estadual do Centro Oeste do Paraná - UNICENTRO. E-mail: elainekbraz@,gmail.com
} 


\section{INTRODUÇÃO}

Notoriamente, questões como Gestão Ambiental, Logística Reversa e Eco-inovação veem sendo inseridas nos mais diversos negócios e nas mais diversas discussões sobre impactos ambientais. Nesse contexto, seja pela lei ou pelas forças opressoras da sociedade, ratifica-se assim, uma mudança nas ações e principalmente nos comportamentos socioculturais, que a partir da inserção de novas ideias ou necessidades, geram formas, técnicas, normas entre outros para minimização dos impactos ambientais ou sua irradicação no meio.

Uma das principais ações pelos agentes governamentais na contemporaneidade, observa-se a sanção de novas leis que direta ou indiretamente modificam e regulamentam novas práticas como a do referido estudo na destinação correta dos resíduos sólidos. No contexto brasileiro esta prática se desenvolveu principalmente com a criação da lei $\mathrm{n}^{\circ} .12 .305$ de 2 de agosto de 2010 da Política Nacional de Resíduos Sólidos que conforme Artigo $3^{\circ}$ inciso VIII versa sobre a disposição final ambientalmente adequada determinando a "distribuição ordenada de rejeitos em aterros, observando normas operacionais específicas de modo a evitar danos ou riscos à saúde pública, à segurança e a minimizar os impactos ambientais adversos" (Lei $\mathrm{n}^{\circ}$ $12.305,2010)$.

Mediantes os novos desafios, as organizações devem estabelecer planos de ações voltadas para o atendimento das normas e legislações em vigência. Assim, a quebra de paradigmas sobre os processos pautados na verticalização precisam ser revistos, a inclusão de diferentes atores e procedimentos se faz necessário, cuja finalidade direciona-se a gestão na busca de soluções.

Desta forma, a logística reversa, que conforme conceituado por Valle (2013, p. 19) “é a área da logística empresarial que opera no sentido inverso, garantindo o retorno de produtos, materiais e peças a um novo processo de produção ou a um novo uso" que acrescentado por Lei $n^{\circ} 12.305$ (2010) no Artigo 3 inciso XII é:

Instrumento de desenvolvimento econômico e social caracterizado por um conjunto de ações, procedimentos e meios destinados a viabilizar a coleta e a restituição dos resíduos sólidos ao setor empresarial, para reaproveitamento, em seu ciclo ou em outros ciclos produtivos, ou outra destinação final ambientalmente adequada.

Portanto, a logística reversa passa a aliar as empresas em suas cadeias de suprimentos fazendo que os diversos resíduos gerados pelo processo de produção retornem ao ciclo produtivo ou a outros negócios (Leite, 2003).

Como estrutura basilar do presente relato, além da introdução, o mesmo foi dividido em mais três partes seguindo o seguinte ordenamento: segunda parte, o contexto da realidade investigada e metodologia da pesquisa; a terceira, refere-se ao diagnóstico da oportunidade e por fim a quarta parte, que versará sobre as contribuições tecnológicas/sociais.

\section{CONTEXTO DA REALIDADE INVESTIGADA E METODOLOGIA DA PESQUISA}

\subsection{Contexto da realidade investigada}

\subsubsection{Caracterização da Organização}

a) Razão Social: Hermann Utri ME.

b) Nome fantasia: Replastik Reciclagem de Plásticos.

c) CNPJ: 09.299.616/0001-80. 
d) Propriedade do capital: Nacional.

e) Setor de atividade e descrição sumária: Industrial. Atua na fabricação de perfis plásticos.

f) Porte: 03 colaboradores. Sua produção é destinada ao município de Guarapuava e Região.

g) Localização: Rua Mary Thompson Milazzo, 1200 - Cep: 85.030-160 - Bairro Jardim das Américas - Guarapuava - Paraná, em frente a BR-277.

h) Principais linhas de produtos: Postes para placas e varais, bancos para jardim, mesas, estrutura para balanços, palanques para cerca, pergolado, trapiches flutuantes, ripas para decks, banquetas, conjuntos para jardim, floreira, namoradeira e projetos exclusivos.

\subsubsection{Breve Histórico da Organização}

A Replastik Reciclagem de plásticos foi fundada em 09/01/2008, por Hermann Utri formado em Engenharia Química. Inicialmente agricultor, acabou iniciando suas atividades no ramo de reciclagem industrial de (PE) Polietileno e (PP) Polipropileno onde atuou até o ano de 2015. Em paralelo, mediante pesquisa, desenvolveu tecnologia própria com a adoção de resíduos de plásticos de variados tipos, que não poderiam ser processados pelo método da reciclagem convencional, provendo novos produtos a partir de toneladas de materiais (reciclados e não recicláveis), prolongamento da vida útil e a reinserção dos mesmos nos canais de distribuição diretos. Assim, toneladas de lixos passam a ser matéria-prima para uma nova geração de produtos.

\subsection{METODOLOGIA DE PESQUISA}

O presente relatório técnico científico que conforme salientado pela Associação Brasileira de Normas Técnicas $(1989$, p. 1) é um "documento que relata formalmente os resultados ou progressos obtidos em investigação de pesquisa e desenvolvimento ou que descreve a situação de uma questão técnica ou científica". Nesse sentido, optou-se pela abordagem de pesquisa qualitativa, que segundo Godoy (1995 p. 58) "envolve a obtenção de dados descritivos sobre pessoas, lugares e processos interativos pelo contato direto do pesquisador com a situação estudada, procurando compreender os fenômenos segundo a perspectiva dos sujeitos".

Esta pesquisa constitui-se do tipo descritiva que visa apresentar as características de uma situação, neste caso um fenômeno, não estabelecendo a explicação sobre o fato descrito (Vergara, 2007). Como fonte e acesso aos dados, foi empregado um roteiro de entrevista semiestruturada composto de duas entrevistas, a primeira realizada dia 12/08/2016 e a segunda dia 16/08/2016 como o proprietário da empresa com duração de 2 horas e 46 minutos.

\section{DIAGNÓSTICO DA OPORTUNIDADE}

A Replastik Reciclagem de Plásticos, foi fundada na cidade de Guarapuava PR e iniciou suas atividades em 2008, tendo como foco a reciclagem de plásticos. Para Valle (2013, p 30) "o processo de reciclagem industrial consiste no reaproveitamento de resíduos industriais, embalagens retornáveis e de materiais constituintes de produtos em final de sua vida útil para a fabricação de novos produtos".

O fundador e microempresário Hermann Utri, enfrentou um problema dentro da sua atividade, pois ao adquirir lotes de materiais que passariam pelo seu processo de reciclagem, 
estes vinham acompanhados de outros resíduos que não poderiam ser reciclados como os plásticos termofixos que, ao serem aquecidos no processo de reciclagem, são degradados e não fundem de forma a permitir a remoldagem. Produtos de EVA (Etil Vinil Acetato) e TNT (Tecido Não Tecido) são exemplos desses produtos.

Hoje $60 \%$ dos resíduos que vem pra reciclagem não podem ser reutilizados, indo para o aterro. (Proprietário)

Em busca de uma solução para dar destino ambientalmente adequado a estes resíduos, o empresário, paralelamente às atividades de reciclagem, começou a desenvolver uma tecnologia própria para aplicar esses resíduos na fabricação de novos produtos. Com o desenvolvimento de nova tecnologia, o empresário optou por encerrar as atividades de reciclagem em 2015 e passou a se dedicar exclusivamente ao novo processo.

Eu construí as duas máquinas, cuja tecnologia é própria, utiliza resíduos de plásticos de diferentes tipos, que não poderiam ser processados pelo método comum de reciclagem. (Proprietário)

Atualmente a empresa conta com três funcionários, onde um atua diretamente na gestão e os demais atuam na produção sob a supervisão do proprietário.

No processo realizado pelo Sr. Hermann não existe uma limitação ou preferência por matéria-prima a ser empregada na produção. São utilizados os plásticos mais diversos: Polietileno de alta densidade (PEAD), Polietileno de baixa densidade (PEBD), Poliestireno (PS), Politereftalato de Etileno (PET), Polipropileno (PP), Polipropileno bi-orientado (BOPP), Policloreto de vinila (PVC). Segundo o proprietário, é indispensável o emprego do polietileno de baixa densidade na mistura para garantir a resistência ao ressecamento do produto final, visto que este tende a ficar exposto às intempéries no seu uso normal. Essa característica foi observada na prática durante o desenvolvimento do processo pelo Sr. Hermann e é passível de ser submetida a estudos técnicos para confirmar essa propriedade.

$\mathrm{O}$ produto da Replastik se enquadra na chamada "madeira-plástica" que tem se difundido muito nos últimos anos. Conforme define Guamá et al. (2008, p. 7), "A madeira plástica é um produto composto de matéria-prima proveniente do lixo plástico reciclado, adicionado de cargas dando ao material propriedades iguais ou até melhores que a da madeira natural. Em alguns casos adiciona-se inclusive serragem da própria madeira”.

A Replastik utiliza os plásticos que não passariam pela reciclagem comum e lhes atribui o reforço de fibras de madeira para garantir a resistência mecânica das peças. Inicialmente, foi utilizada a serragem de madeira como fonte das fibras, mas a empresa conseguiu os melhores resultados aplicando maravalha ao invés da serragem. Segundo o proprietário, a vantagem está no tamanho das fibras.

O processo da Replastik é iniciado por uma separação dos materiais recebidos para reciclagem, segregando os plásticos de outros contaminantes que vêm misturados na carga. Conforme esclarece Forlin e Faria (2002, p. 3 apud Hubner e Frans (1997, p. 328), "a presença de materiais estranhos, como aço, alumínio, vidro, papel/cartão, tintas, vernizes, entre outros, utilizados nos processos de laminação e conversão de materiais plásticos com a finalidade de otimizar ou aumentar a eficiência do sistema de embalagem, constituem-se, igualmente, em contaminantes na reciclagem de embalagens plásticas, bem como os resíduos de alimentos remanescentes na embalagem pós-consumo, ou sujidades adquiridas após o seu descarte". Assim, estes materiais estranhos são segregados e encaminhados para aterro sanitário ou, em alguns casos, encaminhado para outros parceiros para reaproveitamento. 
A seguir, os plásticos passam por uma classificação onde são separados por tipo de material (PP, PVC, PEBD, etc) que, em seguida, são reduzidos a pequenos fragmentos através de um picador. Esse picado é encaminhado para a extrusora onde ele é fundido e aglutinado e, depois, resfriado, ensacado e armazenado. Nessa etapa, a empresa toma o cuidado de segregar materiais coloridos, brancos e incolores. Essa atividade é necessária para permitir a produção de peças com cores diferentes.

De posse de todos os ingredientes já aglutinados, o processo seguinte é o preparo da mistura. O procedimento empregado é bem rudimentar onde os ingredientes selecionados conforme a experiência do proprietário são colocados num misturador na proporção de 4 parcelas de plástico para uma parcela de maravalha, representando uma proporção em volume plástico/madeira de $80 \%$ por $20 \%$.

A mistura pronta é alimentada manualmente na extrusora onde o material plástico é fundido e envolve as fibras de madeira formando uma mistura heterogênea. Essa mistura sai direto da extrusão para a moldagem. Os moldes foram idealizados pelo próprio empresário e são feitos de chapas de aço carbono cortadas, dobradas e soldadas nas formas de "palanques", "ripas" e peças prontas como os "pés" para bancos de jardim e suportes para varal.

Preenchidos os moldes, eles são colocados em um banho de água fria para congelamento do plástico. A seguir, as pontas do molde são abertas e é utilizado um pistão hidráulico para retirar a madeira plástica do interior do molde.

Por fim, é iniciada a montagem dos produtos nos quais se usa a mesma tecnologia usada para a montagem dos móveis de madeira: serras circulares, furadeiras, parafusos, pregos, etc. Conforme o interesse do cliente, as peças são pintadas ou ficam na cor natural do extrudado. 


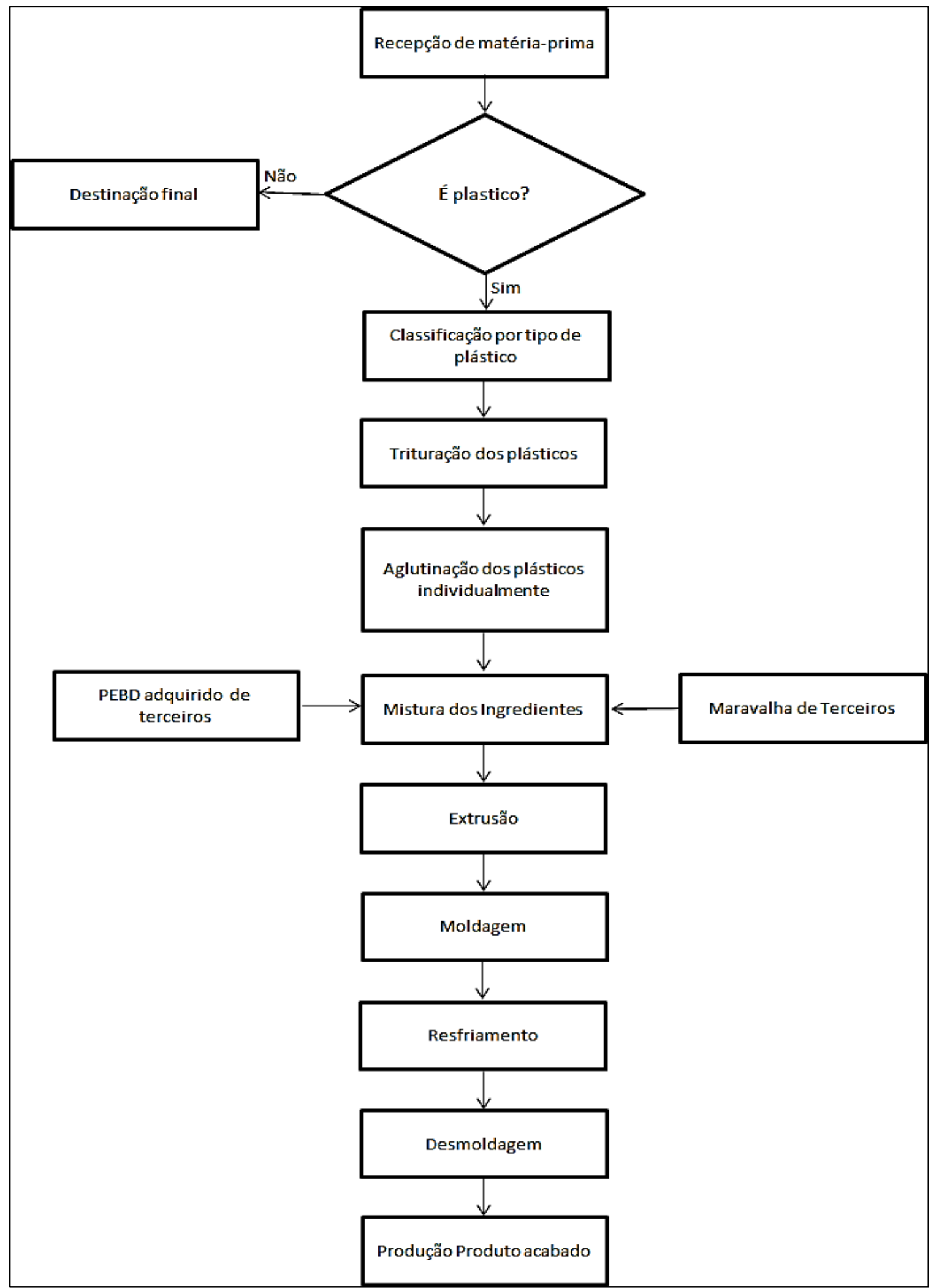

Figura 1. Fluxograma do processo

Fonte: Elaborado pelos autores.

Segundo o proprietário, mesmo não possuindo uma planilha completa de formação do custo de produção, o maior impacto nesse processo é proveniente da energia elétrica utilizada 
na alimentação dos equipamentos. Os demais custos são a maravalha, o PEBD fornecido por uma cooperativa de reciclagem na forma de "sacolas" e o salário dos colaboradores. Os plásticos são, na sua grande maioria, doados pelas empresas que precisam dar um destino ambientalmente adequado aos seus resíduos.

Hoje eu já posso me dar o luxo de escolher material melhor, as empresas mandam para nós. (Proprietário)

Apesar disso, o proprietário da Replastik afirma que a maior dificuldade de comercializar o seu produto é que ainda existe uma discriminação pelos consumidores em relação aos produtos feitos com material reciclado, sendo vistos como material de segunda linha, por exemplo. Segundo ele, esse tem sido o maior empecilho para o crescimento do seu mercado. Nesse sentido, é necessário um trabalho de convencimento do mercado sobre a qualidade do produto e a sua importância na preservação do ambiente.

Outro fator importante é a falta de apoio ao negócio da reciclagem. O Sr. Hermann informou que não conseguiu identificar nenhuma forma de incentivo fiscal disponível que pudesse ajudar a viabilizar o seu empreendimento e a fiscalização e exigências dos órgãos ambientais são maiores na reciclagem do que nas empresas que usam matéria-prima virgem. Tudo isso, desestimula o investimento nesse ramo.

Os principais produtos da Replastik são mesas e cadeiras para jardim, balanços infantis, namoradeiras, postes para varal, galerias pluviais e cochos para ração animal de bovinos.

\section{CONTRIBUIÇÃO TECNOLÓGICA/SOCIAL}

Mediante os fundamentos teóricos e as práticas ratificadas na empresa Replastik, constata-se alguns paradoxos, pois ao mesmo tempo que a importância das suas atividades e processos se fazem para a sociedade, pouco são os incentivos governamentais para sua efetivação no mercado.

Com a observação, averígua-se um proprietário que perante os desafios providos de medidas governamentais que o fizeram perder suas terras, se vê motivado a "novos ares". Assim, nasce a Replastik pautada na reciclagem industrial (convencional) e na prospecção do ideário de seu fundador que acreditou neste processo com uma fonte de benfeitoria para a sociedade e de uma oportunidade de negócio.

Constatou-se um empreendimento consolidado enquanto ideologia de ação e de importância salutar para a sociedade pelos fins que oportunizam a muitos produtos. Hoje sua empresa não opera mais no ramo ou atividade de reciclagem industrial (convencional), mas vale-se de estrutura própria, de equipamentos e maquinarias (próprias) para o processamento de resíduos sólidos que anteriormente não tinham a possibilidade de reinserção no fluxo direto (logística reversa); a empresa se apresenta como uma incubadora pelas práticas vigentes tanto no processo de produção como na busca por novos produtos mediante as prototipagens (próprias) e também econômica (fins lucrativos), bem como, um exemplo de conscientização e adoção de ações ou medidas para a minimização dos impactos ambientais.

Nesse sentido, conota-se que conceitos como gestão ambiental, logística reversa e ecoinovação permeiam toda essa organização. São temáticas implícitas voluntariamente, sem a necessidade de subterfúgios para sua prática e concepção.

Nesta forma, tanto no aspecto governamental como nos aspectos que tangem a sociedade civil como um todo, a conscientização está indiretamente proporcional as práticas (pragmatismo) no dia-a-dia, pois sabe-se da premência de ações individuais e coletivas para a 
minimização dos impactos ambientais, mas poucas são as ações que contemplam a possibilidade de reinserção ou criação de novos produtos no fluxo direto ou direto da cadeia de distribuição.

\section{REFERÊNCIAS}

Associação Brasileira de Normas Técnicas. (1989). NBR 10719. Apresentação de relatórios técnico-científicos. Rio de Janeiro.

Lei $n^{\circ} 12.305$ de 02 de agosto de 2010 (2010). Política Nacional de Resíduos Sólidos. $\begin{array}{lllll}\text { Recuperado em } & 25 & \text { de } & \text { novembro, } & 2016 .\end{array}$ http://www.planalto.gov.br/ccivil_03/_ato2007-2010/2010/lei/112305.htm

Forlin, F. J., \& Faria, J. A. (2002). Considerações sobre a Reciclagem de Embalagens Plásticas. Ciência e Tecnologia, 12 (1), 1-10.

Godoy, A. S. (1995). Introdução à Pesquisa Qualitativa e suas Possibilidades. Revista de Administração de Empresas. 35 (2), 57-63.

Guamá, F. F. M C., Costa, R. V. De A., Rocha, H. L., Isensee, F. V., \& Futuro, L. L. (2008) Lixo plástico - de sua produção até a madeira plástica. XXVIII Encontro Nacional de Engenharia de Produção. Rio de Janeiro.

Leite, P. R. (2003). Logística Reversa: meio ambiente e competitividade. 2 ed. São Paulo: Pearson Prentice Hall.

Valle, R., \& Souza, R. G. (2013) Logística Reversa: processo a processo. São Paulo: Atlas.

Vergara, S. C. (2007) Projetos e relatórios de pesquisa em administração (8a ed). São Paulo: Atlas. 